Erratum to Volume 38, Number 11, November 2009, pp. 2308-2313

\title{
Erratum to: In Situ Measurements of Thermal and Electrical Effects of Strain in Flip-Chip Silicon Dies Using Synchrotron Radiation X-rays
}

\author{
ALBERT T. WU, ${ }^{1,4}$ CHUN-YANG TSAI,${ }^{1}$ CHIN-LI KAO,${ }^{2}$ MENG-KAI SHIH, ${ }^{2}$ \\ YI-SHAO LAI, ${ }^{2}$ HSIN-YI LEE, ${ }^{3}$ and CHING-SHUN KU ${ }^{3}$ \\ 1.-Department of Chemical and Materials Engineering, National Central University, \\ Jhongli City 320, Taiwan. 2.-Advanced Semiconductor Engineering, Kaohsiung 811, Taiwan. \\ 3.-National Synchrotron Radiation Research Center, Hsinchu 300, Taiwan. 4.-e-mail: atwu@ \\ ncu.edu.tw
}

Erratum to: Journal of ELECTRONIC MATERIALS DOI 10.1007/s11664-009-0934-9

This paper was submitted and selected for the lead-free solder special issue. It was inadvertently published in an earlier issue this year. 